\title{
ESTABLISHING ENGINEERING S-CURVES TO EVALUATE SUPERVISION ENGINEER ALLOCATIONS FOR HIGHWAY CONSTRUCTION PROJECTS
}

\author{
Shih-Hsu WANG ${ }^{\mathrm{a}}$, Wei-Chih $\mathrm{WANG}^{\mathrm{b}}$, Pei-Yuan HSU ${ }^{\mathrm{b}}, \mathrm{Ci}-\mathrm{Hao} \mathrm{CHEN}^{\mathrm{b}}$, Kun-Chi WANG ${ }^{\mathrm{b}}$ \\ ${ }^{a}$ Department of Civil Engineering, R.O.C. Military Academy, No. 1, Wei-Wu Road, \\ Fengshan District, Kaohsiung 830, Taiwan \\ ${ }^{b}$ Department of Civil Engineering, National Chiao Tung University, 1001, University Road, \\ Hsin-Chu 300, Taiwan
}

Received 17 Nov 2013; accepted 20 Mar 2014

\begin{abstract}
An engineering consultant firm needs to allocate engineers to supervise a highway construction project in each month during the construction phase. Properly assigning the supervision engineers under a cost-plus-fixed-fee contract has been a key factor affecting the profitability of the firm and the quality assurance of the project. Assigning too many engineers will be a waste, while allocating too few engineers may harm the supervision quality. This work proposes a two-stage model to develop engineering S-curves (called ES-curves) for planning and controlling the engineering supervision schedule. In the planning stage, a predictive ES-curve model is established based on historical ES-curves. In the controlling stage, an ES-curve is built according to the relationships between the engineering progress and construction progress. A cluster analysis and regression analysis are applied to the model development. A case study demonstrates that the produced ES-curves can help management in planning and evaluating when to increase or decrease the number of supervision engineers assigned to a project.
\end{abstract}

Keywords: S-curve, supervision engineers, resource allocation management, engineering consultant firms, cluster analysis, regression analysis.

\section{Introduction}

The Taiwanese government has spent an average of approximately $\$ 670$ million US dollars annually on numerous highway construction projects during the period 2003 to 2012 (TANEEB 2012). The construction qualities of these projects greatly influence the country's economic development and the comfort level of taxpayers. The project client or owner (called the Taiwan Area National Expressway Engineering Bureau, or TANEEB) has adopted a form of cost-plus-fixed-fee contract to manage the entrusted supervision companies (i.e. engineering consulting firms) to appropriately supervise the quality of construction work performed by of various contractors.

Although TANEEB views the contract as a costplus-fixed-fee one, an upper limit of the total supervision manpower (i.e. total man-months) is determined at the outset. Unless the contractual work is altered (e.g. additional construction work caused by change orders increases the amount of supervision work), this upper limit of total man-months remains. Under this limit, an entrusted consulting firm is reimbursed according to the number of engineers (i.e. man-months) allocated.
While assigning too many engineers is inefficient and likely to exceed the upper limit, assigning too few engineers makes it impossible for them to monitor the overall quality of the construction work effectively (Chen 2011). Preferably, the consulting firm should consume the total supervision man-months (in order to charge all of the contractual costs) immediately when the whole construction work is completed. Thus, properly planning the required consulting engineers to supervise a highway construction project throughout the construction phase greatly affects the profitability of the engineering consultant firms.

In practice, prior to the construction, an engineering firm must develop an engineer-allocation schedule to plan when and how many engineering man-months will be spent on the project. This schedule is mainly designed according to the practitioners' experience. During the construction phase, the problem is how to adjust the planned engineering schedule to respond to current construction progress. So far, no practical tools or academic models have been devised to deal with this problem.

This work proposes a two-stage model to develop engineering S-curves (called ES-curves) for planning

Corresponding author: Wei-Chih Wang

E-mail:weichih@mail.nctu.edu.tw 
and controlling the engineering supervision schedule. In the planning stage, a predictive ES-curve model is established based on historical ES-curves. In the controlling stage, an ES-curve is built according to the relationships between the engineering progress and construction progress. A cluster analysis and regression analysis are applied to the model development.

\section{Past research}

\subsection{Consulting fees}

Several studies have investigated the reasonableness of consulting fees (Bubshait et al. 1998; Feldmann et al. 2008). To obtain a high quality of technical service, a technical service provider (consulting firm) must be compensated with a fair service fee; a charge concept acceptable to most proprietors or project clients (Hoxley 2000; Ling 2004). However, many studies have indicated a significant disparity between the service fee determined by the project clients and the cost deemed reasonable by consulting firms (Flyvbjerg et al. 2002; Molenaar 2005; Gransberg et al. 2007). Researchers in the past usually recommended addressing this cost difference issue by adjusting the service fee rate (Carr, Beyor 2005; Bubshait et al. 1998). However, the rate is affected by a consultant's qualifications, service quality, and service scope. A project client usually will not agree to an increased service fee if charge conditions remain unchanged.

\subsection{Engineering manpower allocation}

Very few models have been developed specifically for dealing with the resource (engineer) allocation problems of construction supervision projects. For example, Li (2004) developed an integer programming method to assign supervision engineers to multiple building projects with an objective of minimizing supervision costs. However, applying this method in practice is not easy, because many critical assumptions must be made in advance, such as monthly workloads required (in terms of costs), the monthly workload provided by each engineer, and the percentages of time each type of engineer will be assigned to the different projects.

Other studies have focused on allocating engineering manpower to design projects (but not supervision projects). For instance, Ogunlana et al. (1998) devised a system dynamic (SD) model to manage the detailed design process of an engineering project. They used SD modelling to experiment with possible scenarios to examine the effectiveness of various policies (or strategies), including progress control, manpower allocation, estimation of workload, and the realization of underestimated work, in meeting different management objectives. These objectives included meeting schedules, minimizing labor days expended, and reducing the cost of design. Running the model requires detailed data, which are usually not well recorded (Ogunlana et al. 1998), including planned man-hours/days, planned manpower loading, total documents produced, average design productivity (documents per man-day), amount of rework, and effort spent checking and reworking.

Moreover, Yang and Chou (2011) identified that finding a systematic way to assign consulting staff to incoming projects to ensure profitability is important to a consulting engineering company. They developed a multiobjective optimization model to assist consulting engineering firms in assigning engineering teams to incoming projects over a planning time horizon. The multiple objectives they considered included maximizing the overall profit, minimizing the variation of workloads, minimizing the maximal overtime, and maximizing the average utilization percentage. In addition, their model focused on the team level, not the engineer level.

\subsection{S-curves for construction control}

An S-curve is a graphical representation of the cumulative progress of a construction project, from start to finish. The S-curve is normalized according to two basic parameters, namely the relevant quantity total (e.g. project costs) and the duration of the project. The vertical scale shows the cumulative project progress in dollars or as percentage completed. The horizontal scale shows time (Cioffi 2005; Chao, Chien 2009). The shape of the S-curve usually has a smaller slope at the beginning and near the end and a larger slope in the middle, indicating that progress is slow in mobilization and demobilization periods, but faster when the bulk of the work takes place (Chao, Chien 2009).

S-curves have been widely used in project controls of construction projects and are valuable in reporting the status and predicting the future of projects (Miskawi 1989). For example, in application schedule control, a planned S-curve is used as the target against the actual progress at any point in time during the implementation phase of a construction project to evaluate whether the project is on schedule (Cioffi 2005).

Several management tools have been proposed based on the concept of an S-curve. For instance, earned value techniques use S-curve-based parameters to derive a management index to support project costs and schedule control (Fleming, Koppelman 2005; Cioffi 2006; Warburton 2011). Cheng et al. (2011) developed a mathematical model to forecast the short-interval (i.e. four-month) actual S-curve of expenditure from a general contractor's point of view. By considering project cash flows in activity networks with fuzzy durations and costs, Maravas and Pantouvakis (2012) developed project optimistic and pessimistic S-surfaces to assist in risk management.

So far, all previous S-curve models have focused on construction progress, but no models have been designed to manage the engineering progress of construction supervision projects (Chen 2011).

\section{Analysis of current practice in Taiwan}

When the design of a highway project is almost finished, an engineering consulting company is selected by the 
project client (TANEEB) to supervise the incoming construction work comprising a mixture of many roads, bridges, and tunnels. If the volume of construction work is high, it is usually divided into several contracts and executed by various contractors. In that case, the engineering firm is responsible for a mega supervision project that supervises the overall construction work conducted by multiple contractors.

The TANEEB applies a cost-plus-fixed-fee method to a supervision contract to ensure that the entrusted consulting company will allocate sufficient onsite engineers to satisfactorily supervise the jobs. Under such a contract, the consulting company must first submit an engineer allocation plan/schedule that indicates the types and number of supervision managers/engineers assigned to the project. To do so, the consulting firm will usually devise a supervision organization of the project.

Figure 1 displays an example of the organization of a mega supervision project. In this example, the project has a project manager, a supervisor, and a vice supervisor in the project section. The organization also has four functional sections (contract, $\mathrm{Q} / \mathrm{A}$, surveying, and safety sections) and four supervision sections (to supervise the four construction contractors). Table 1 presents the engineer allocation schedule for this example project. Table 1 also indicates that this example project has a total of 1,277 man-months with a duration of 57 months of project supervision (from May 2007 to February 2012). Notably, several factors influence the development of this engineering allocation schedule, including project size, project complexity, construction interfaces, construction specification requirements, and site conditions. However, this schedule is devised mainly based on practitioner experience.
Next, the TANEEB needs to review and approve the submitted schedule before it becomes an as-planned engineer allocation schedule. This as-planned schedule specifies the sum of the man-months (SM) for all managers and engineers in each month (e.g. the "sub-total man-months" at the bottom of Table 1), the cumulative man-months in each month, and the total man-months (TM) for the whole project. Notably, the approved TM is the aforementioned upper limit.

As construction proceeds, the consulting firm uses this as-planned schedule as a target schedule to assign engineers. They will avoid allocating more engineers than specified in the as-planned sub-total man-months for each month and the total man-months for the whole project, unless absolutely necessary. The TANEEB also uses this schedule to monitor how the consultant allocates man-months to the project.

The consulting firm may need to update this asplanned engineer allocation schedule according to the construction progress. For instance, if construction is delayed, they should hold off on assigning additional engineers until the construction progress has caught up with the schedule. A revised schedule also needs to be reviewed and approved by the TANEEB.

Generally, allocating too many engineers in a situation of slow or delayed construction progress will be a waste of engineers because the man-months may be insufficient to supervise the rest of the project. Conversely, assigning too few engineers may harm the supervision quality because certain supervision work may be ignored. While current practice is experience based, a tool that can help generate or update the engineering schedule should be useful in supporting supervision management when allocating engineers.

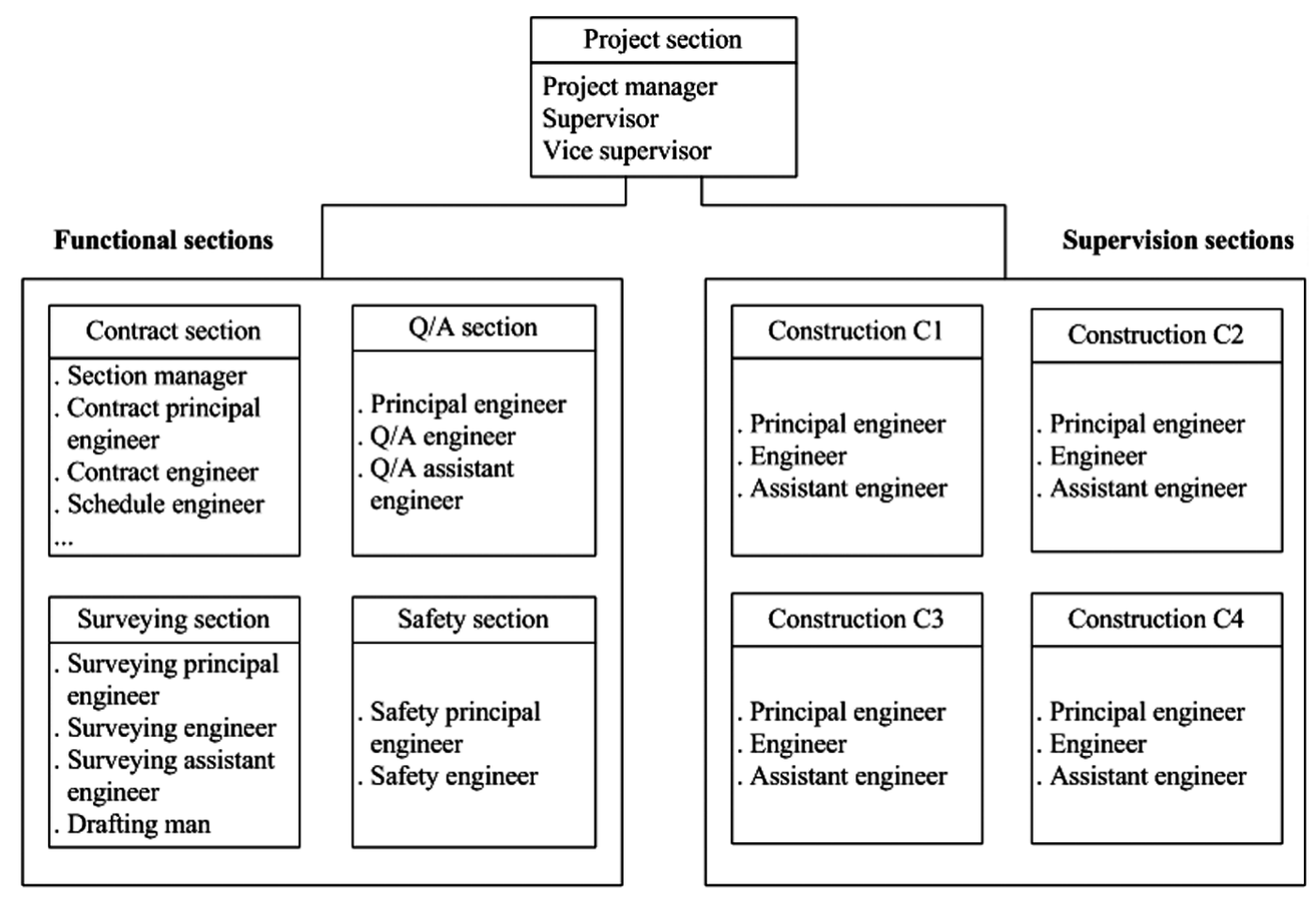

Fig. 1. Example of the organization of a mega supervision project 


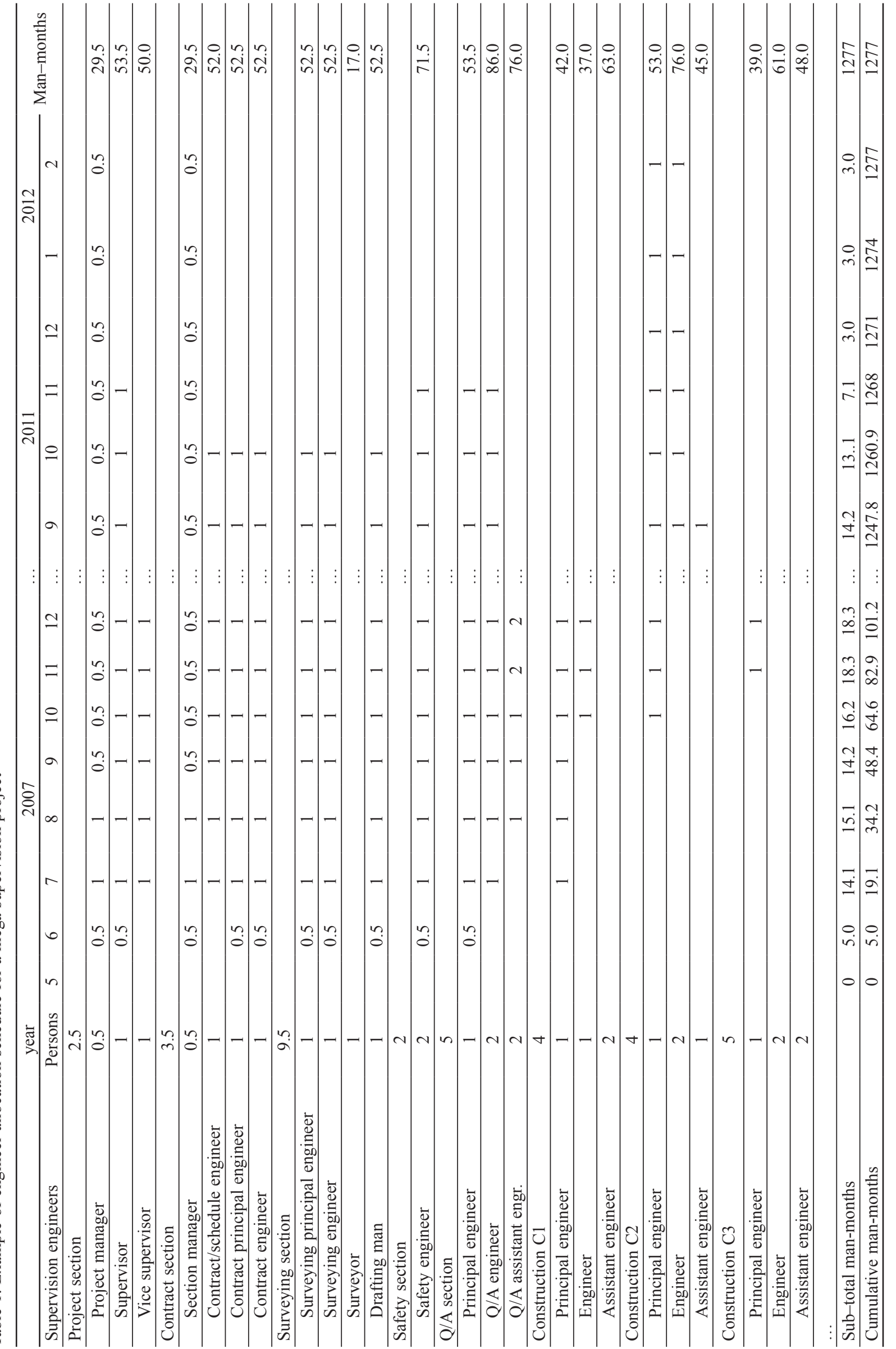




\section{Proposed model}

Based on the as-planned engineer allocation schedule shown in Table 1, this work proposes to establish an engineering S-curve (ES-curve), similar to construction S-curves, to support allocating supervision engineers. In this ES-curve, the horizontal axis displays the duration of supervision as a percentage and the vertical axis shows the cumulative progress of allocated man-months as a percentage.

The proposed model is divided into two stages, namely, a planning and a controlling stage, depending on whether or not the construction schedules are available. In the planning stage, the construction schedules are unavailable and the proposed model applies a regression analysis to derive an ES-curve directly from historical ES-curves. In the controlling stage, the construction project schedules are available. The proposed model uses a cluster analysis to categorize the progress differences (between the engineering progress and construction progress), applies a regression analysis to generate predictive equations for the progress differences, and then develops an ES-curve.

\subsection{Development of an ES-curve model in the planning stage}

In the planning stage, the approved ES-curves of six historical highway supervision projects are used. To build the ES-curve of a project, the percentages of the supervision duration (the $x$-axis) and their corresponding cumulative progress percentages (the $y$-axis) are processed. For instance, Table 2 displays the calculations for the percentages of the supervision duration (the $x$ axis) and their corresponding cumulative progress percentages (the $y$-axis) in each month for the same example shown in Table 1. Consider the second month (July 2007) as an illustration. The supervision duration percentage is $3.51 \%(=2 / 57)$, while the corresponding cumulative progress percentage is $1.5 \%(=19.1 / 1,277)$.
As a result, the ES-curve of the project can be plotted in an $x-y$ plan. The ES-curves of the other five historical projects were built in a similar way.

Using the software SPSS, various equation types (such as Sigmoid, Logistic, Weibull, and Gompertz) are tested to fit these six historical data shown in the same $x-y$ plan. The Sigmoid equation type with four parameters is identified as having the R-square value of 0.9946 , indicating that this nonlinear equation could explain a high percentage of the variance in the dependent variable (i.e. cumulative engineering progress) (Ratkowsky 1990; Draper, Smith 1998).

Figure 2 displays the derived regression line of the ES-curve in the planning stage. That is, in the planning stage, the value of the cumulative engineering progress, $y_{x}$ (a percentage), at supervision time $x$ (in percentage) is calculated as follows:

$$
y_{x}=-0.126+\frac{1.2911}{1+e^{-\left(\frac{x-0.5352}{0.2277}\right)}} .
$$

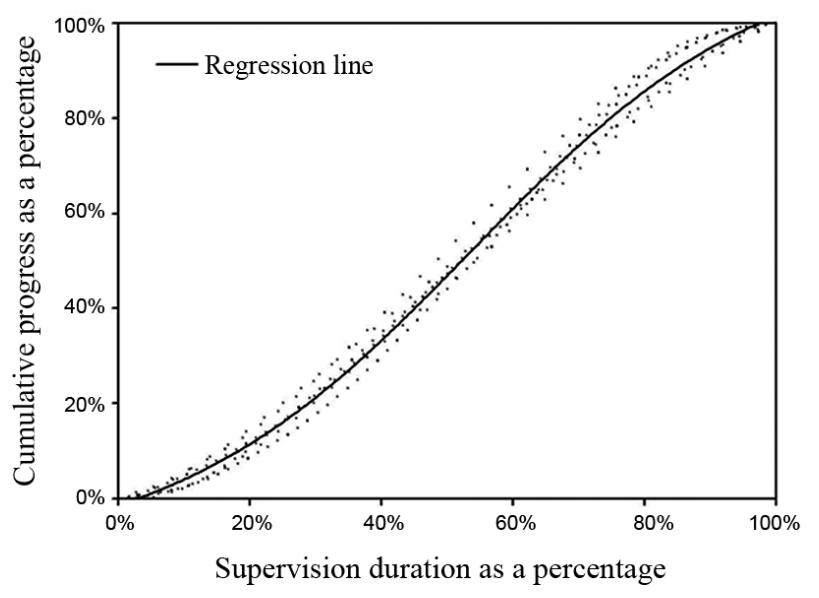

Fig. 2. Derived regression line of ES-curve in the planning stage

Table 2. Data of the supervision duration and cumulative progress for the same example project shown in Table 1

\begin{tabular}{|c|c|c|c|c|c|c|c|c|c|c|c|c|c|c|c|}
\hline Year & & & & & 2007 & & & & $\ldots$ & & 20 & 11 & & 20 & 12 \\
\hline Month & 5 & 6 & 7 & 8 & 9 & 10 & 11 & 12 & $\ldots$ & 9 & 10 & 11 & 12 & 1 & 2 \\
\hline $\begin{array}{l}\text { Number of } \\
\text { month }\end{array}$ & 0 & 1 & 2 & 3 & 4 & 5 & 6 & 7 & $\ldots$ & 52 & 53 & 54 & 55 & 56 & 57 \\
\hline $\begin{array}{l}\text { Supervision } \\
\text { duration as } \\
\text { a percentage } \\
(x \text {-axis) }\end{array}$ & 0 & $\begin{array}{l}1.75 \% \\
(1 / 57)\end{array}$ & $\begin{array}{l}3.51 \% \\
(2 / 57)\end{array}$ & $\begin{array}{l}5.26 \% \\
(3 / 57)\end{array}$ & $\begin{array}{l}7.02 \% \\
(4 / 57)\end{array}$ & $\begin{array}{l}8.77 \% \\
(5 / 57)\end{array}$ & $\begin{array}{c}10.53 \% \\
(6 / 57)\end{array}$ & $\begin{array}{l}12.28 \% \\
(7 / 57)\end{array}$ & $\ldots$ & $\begin{array}{l}91.23 \% \\
(52 / 57)\end{array}$ & $\begin{array}{l}92.98 \% \\
(53 / 57)\end{array}$ & $\begin{array}{l}94.74 \% \\
(54 / 57)\end{array}$ & $\begin{array}{l}96.49 \% \\
(55 / 57)\end{array}$ & $\begin{array}{l}98.25 \% \\
(56 / 57)\end{array}$ & $\begin{array}{l}100 \% \\
(57 / 57)\end{array}$ \\
\hline $\begin{array}{l}\text { Sub-total } \\
\text { man months }\end{array}$ & & 5.0 & 14.1 & 15.1 & 14.2 & 16.2 & 18.3 & 18.3 & $\ldots$ & 14.2 & $13 . .1$ & 7.1 & 3.0 & 3.0 & 3.0 \\
\hline $\begin{array}{l}\text { Cumulative } \\
\text { subtotal } \\
\text { man-months }\end{array}$ & 0 & 5.0 & 19.1 & 34.2 & 48.4 & 64.6 & 82.9 & 101.2 & $\ldots$ & $1,247.8$ & $1,260.9$ & 1,268 & 1,271 & 1,274 & 1,277 \\
\hline $\begin{array}{l}\text { Cumulative } \\
\text { progress as } \\
\text { a percentage } \\
\text { (y-axis) }\end{array}$ & 0 & $0.4 \%$ & $1.5 \%$ & $2.7 \%$ & $3.8 \%$ & $5.1 \%$ & $6.5 \%$ & $7.9 \%$ & & $97.7 \%$ & $98.7 \%$ & $99.3 \%$ & $99.5 \%$ & $99.8 \%$ & $100 \%$ \\
\hline
\end{tabular}




\subsection{Development of the ES-curve model in the controlling stage}

Since supervision engineers are needed according to the progress of the construction, the engineering progress should highly relate to the construction progress during any point in the construction period. In the controlling stage, given that the construction schedules are available, the steps to develop an ES-curve are as follows:

1. Step 1: Establish the engineering and construction S-curves for each historical project.

2. Step 2: Calculate the progress differences between the engineering and construction S-curves for each historical project.

3. Step 3: Use cluster analysis to categorize the progress differences for each historical project.

4. Step 4: Use regression analysis to derive prediction equations for the progress differences for each zone of each project.

5. Step 5: Integrate the regression results across all historical projects.

Next, the ES-curve developed from steps 1 5 can be applied to estimate the engineering progress of a new project.

\section{Preparation of historical projects}

Four historical mega supervision projects (i.e. project A, $\mathrm{B}, \mathrm{C}$, and $\mathrm{D}$ ) comprising 18 highway construction projects are used to develop the controlling-stage ES-curve model. The left of Table 3 shows the project number for each construction project. For example, mega supervision project A contains five construction projects, namely, A1, A2, ..., and A5. Project A has a total of 4,171 man-months.

As indicated earlier, the organization of a mega supervision project includes two parts, namely, a functional section and a field supervision section. Before developing the ES-curve model, the total man-months (MMs) for each mega project must be processed to obtain the man-months allocated to construction project $i$ (denoted as $z_{i}$ ). The value of $z_{i}$ is calculated as follows:

$$
\begin{gathered}
z_{i}=\left(m \times p_{i}\right)+n_{i} ; \\
p_{i}=q_{i} / \text { Tot },
\end{gathered}
$$

where $q_{i}$ is the (contractual) construction cost of project $i ; p_{i}$ is the construction cost of project $i$ as a percentage of the total construction cost (denoted as Tot) for all construction projects under the mega project; and $m$ is the total contractual MMs allocated to the function sections across all projects. The value of $m \times p_{i}$ represents the MMs allocated to the function section of project $i$, assuming that $\mathrm{m}$ is shared according to the scale construction cost, and $n_{i}$ is the MMs assigned to the supervision section of project $i$. Then, the MMs allocated to project $i$ (i.e. $z_{i}$ ) is equal to the sum of the MMs allocated to the function section (i.e. $\left.m \times p_{i}\right)$ and the supervision section $\left(n_{i}\right)$.

\begin{tabular}{|c|c|c|c|c|c|}
\hline \multirow{2}{*}{$\begin{array}{l}\text { Construction } \\
\text { project No. }\end{array}$} & \multirow{2}{*}{$\begin{array}{l}\text { Construction cost }(\$) \\
(q)\end{array}$} & \multirow{2}{*}{$\begin{array}{l}\% \text { of construction } \\
\text { cost }(p=q / T o t)\end{array}$} & \multicolumn{2}{|c|}{ Man-months } & \multirow{2}{*}{$\begin{array}{l}\text { Man-months } \\
(z=m \times p+n\end{array}$} \\
\hline & & & Functional $(m)$ & Supervision $(n)$ & \\
\hline A1 & $4,239,333,000$ & $23.63 \%$ & \multirow{6}{*}{2,220} & 385 & 909.59 \\
\hline $\mathrm{A} 2$ & $3,183,470,000$ & $17.74 \%$ & & 390 & 783.83 \\
\hline A3 & $4,499,413,979$ & $25.08 \%$ & & 437 & 993.78 \\
\hline A4 & $3,099,972,342$ & $17.28 \%$ & & 345 & 728.62 \\
\hline A5 & $2,920,587,218$ & $16.28 \%$ & & 394 & 755.18 \\
\hline Total cost $(T o t)$ & $17,942,776,539$ & $100 \%$ & & 4,171 & 4,171 \\
\hline B1 & $2,421,889,000$ & $21.47 \%$ & \multirow{6}{*}{1,257} & 234.5 & 504.38 \\
\hline B2 & $2,186,858,358$ & $19.39 \%$ & & 244 & 487.73 \\
\hline B3 & $2,982,150,000$ & $26.44 \%$ & & 249 & 581.35 \\
\hline B4 & $1,986,942,000$ & $17.61 \%$ & & 225.5 & 446.86 \\
\hline B5 & $1,702,609,000$ & $15.09 \%$ & & 218 & 407.68 \\
\hline Total cost & $11,280,448,358$ & $100 \%$ & & 2,428 & 2,428 \\
\hline $\mathrm{C} 1$ & $1,266,138,000$ & $15.06 \%$ & \multirow{5}{*}{900.06} & 141.56 & 277.11 \\
\hline $\mathrm{C} 2$ & $2,107,597,000$ & $25.07 \%$ & & 156.42 & 382.07 \\
\hline $\mathrm{C} 3$ & $2,268,396,000$ & $26.99 \%$ & & 207.56 & 450.49 \\
\hline $\mathrm{C} 4$ & $2,763,462,000$ & $32.88 \%$ & & 173.4 & 469.34 \\
\hline Total cost & $8,405,593,000$ & $100 \%$ & & 1,579 & 1,579 \\
\hline D1 & $2,820,133,814$ & $32.81 \%$ & \multirow{5}{*}{908.71} & 187.45 & 485.6 \\
\hline D2 & $1,374,071,000$ & $15.98 \%$ & & 177.17 & 322.38 \\
\hline D3 & $3,300,945,000$ & $38.40 \%$ & & 164.46 & 513.4 \\
\hline D4 & $1,100,908,680$ & $12.81 \%$ & & 97.21 & 213.62 \\
\hline Total cost & $8,596,058,494$ & $100 \%$ & & 1,535 & 1,535 \\
\hline
\end{tabular}

Table 3. Man-months allocated to each construction project of four mega supervision projects 
Table 3 summarizes the calculated MMs allocated to each construction project. For example, mega project A has 4,171 man-months in total. These MMs are divided into $909.59,783.83,993.78,728.62$, and 755.18 MMs to supervise the five construction projects A1, A2, A3, A4, and A5, respectively. The calculation details for these MMs can be found in Chen (2011).

After calculating the total MMs for each construction project $i$, the MMs of the $j$ th month for the project (denoted as $\left.M M_{i(j)}\right)$ is calculated as follows:

$$
M M_{i(j)}=\left(m_{j} \times p_{i}\right)+n_{i(j)},
$$

where $m_{i}$ is the total MMs allocated to the function sections in the $j$ th month, and $n_{i(j)}$ is the MMs assigned to the supervision section of project $i$ in the $j$ th month.

\subsection{Step 1: Establish the engineering and construction S-curves for each historical project}

After using Eqn (4) to calculate the MMs for each month of project $i$ (that is, $M M_{i(j)}$ ), the cumulative MMs as a percentage of each month (and the supervision time as a percentage) can then be obtained. Consequently, an EScurve for each construction project $i$ can be established. In addition, a construction S-curve is obtained in the conventional way. Thus, the ES-curve and construction S-curve can be plotted together for each construction project. For example, Figure 3 shows the engineering and construction S-curves of project A1.

\subsection{Step 2: Calculate the progress differences between the engineering and construction S-curves for each historical project}

This step collects data of the progress differences between the engineering and construction progress at any point during supervision. The difference between the two progresses in the $j$ th month for project $i$ (denoted as $\left.\Delta y_{i(j)}\right)$ is calculated as follows:

$$
\Delta y_{i(j)}=e n g_{i(j)}-\operatorname{con}_{i(j)},
$$

where $e n g_{i(j)}$ and $\operatorname{con}_{i(j)}$ are the cumulative progresses (as percentages) of the engineering and construction progress in the $j$ th month of project $i$.

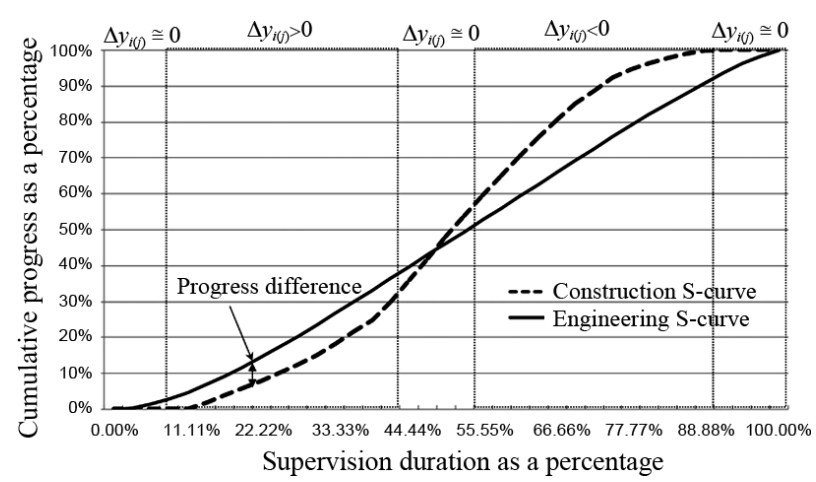

Fig. 3. Example of the engineering and construction S-curves for project A1
Take project A1 as an example (see Fig. 3). The total supervision duration is 36 months. When the supervision duration is in the 8 th month (i.e. $22.22 \%$ of the 36 months), the values of the cumulative engineering progress $\left(e n g_{i(j)}\right)$ and cumulative construction progress $\left(\right.$ con $\left._{i(j)}\right)$ are $14.53 \%$ and $7.98 \%$, respectively. Thus, the progress difference $\left(\Delta y_{i(j)}\right)$ is $6.55 \%(=14.53-7.98 \%)$. A positive value of $\Delta y_{i(j)}$ indicates that the engineering progress is ahead of the construction progress, and vice versa. Figure 3 also shows that is positive in the first half part of the project, but negative in the latter half of the project.

\subsection{Step 3: Use a cluster analysis to categorize the progress differences for each historical project}

Instead of using a single regression equation to predict the progress differences for the overall project supervision, this study develops five regression equations with respect to the five duration zones of project supervision. For example, in Figure 3, the progress differences can easily be classified into five zones, namely, $\Delta y_{i(j)}>0$ (in the front half), $\Delta y_{i(j)} \cong 0$ (at the beginning, in the middle, and at the end), and $\Delta y_{i(j)}<0$ (in the latter half). The steps to conduct the cluster analysis are as follows:

1. Step 3.1: Input the progress difference data, $\Delta y_{i(j)}$, (from the first month to the last month of the project supervision) for each historical project. For example, the construction of project A1 lasted 36 months. The progress difference data are $0.21 \%$, $1.47 \%, \ldots,-1.82 \%$, and $0.00 \%$ from the first month to the 36th month, respectively.

2. Step 3.2: Apply hierarchical cluster and K-means cluster analyses to classify the progress difference data $\left(\Delta y_{i(j)}\right)$ to define the various zones of each historical project. Hierarchical cluster and K-means are two common cluster analysis methods. Similar to Milligan (1980) and Fisher et al. (1992), this study exploits the advantages of both methods to yield the smallest variances of the $\Delta y_{i(j)}$ values within each cluster and lead to statistically significant differences of the means of the $\Delta y_{i(j)}$ values among clusters. To do so, the appropriate number of clusters is first determined using the hierarchical cluster. In each cluster, the mean of the $\Delta y_{i(j)}$ values is generated. The means of all clusters are then used as the initial seeds for the K-means cluster analysis. Additionally the hierarchical cluster and K-means cluster analyses are performed using a statistical data analysis system, SPSS.

3. Step 3.3: Select suitable number of clusters. Researchers such as Sharma (1996) have suggested using the Root-Mean-Square Standard Deviation (RMSSTD), coefficient of determination $\left(\mathrm{R}^{2}\right)$ and Semi-Partial R-Square (SPRSQ) to determine whether the resulting number of clusters is appropriate. RMSSTD measures homogeneity within each cluster by summing the standard deviations (STDs) of the clusters. A lower RMSSTD value indicates high homogeneity in each cluster. 
The value of $\mathrm{R}^{2}$ is equal to one minus the ratio of the variance before clustering and after clustering. If the number of clusters and the number of progress difference data are the same, $\mathrm{R}^{2}$ is equal to one. If all progress difference data are placed in only one cluster, $\mathrm{R}^{2}$ is equal to 0 . A higher $\mathrm{R}^{2}$ value generally implies improved clustering because more progress difference data are categorized into various clusters to develop more reliable fit regression equations. However, too many clusters are difficult to manage, e.g., requiring additional duration zones for analysis. SPRSQ determines if some intermediate clusters should be combined in the clustering process by measuring the difference in $\mathrm{R}^{2}$ when the number of clusters changes. A small SPRSQ value refers to a situation in which the combination of clusters does not increase high variances (i.e. the data in each combined cluster resemble each other); this combination is thus acceptable. Conversely, a high SPRSO value (i.e. the data in each combined cluster are highly varied) implies that current clusters should be further disaggregated. Overall, a clustering number with low RMSSTD, high $\mathrm{R}^{2}$, and low SPRSQ is preferred. In addition, this clustering number should be as small as possible.

For example, Table 4 displays the values of RMSSTD, $\mathrm{R}^{2}$, and SPRSQ associated with various numbers of clusters (i.e. 2 7 clusters) for project A1. In the table, it can be found that the values of RMSSTD (1.0516; too high), $\mathrm{R}^{2}$ (0.1059; too low), and SPRSQ (0.9717; too high) evaluated for the twocluster situation are not suitable. It is preferred that the data $\left(\Delta y_{i(j)}\right)$ are grouped into more than two clusters (i.e. from three to seven clusters) because the values of RMSSTD, $\mathrm{R}^{2}$, and SPRSQ are more suitable. Finally, since the smallest number of clusters is preferred, the progress differences are divided into three clusters as follows: $\Delta y_{i(j)}>0$ (in the first half), $\Delta y_{i(j)} \cong 0$ (at the beginning, in the middle, and at the end), and $\Delta y_{i(j)}<0$ (in the latter half).

4. Step: 3.4: Generate the clusters. Table 5 displays the progress differences classified per zone. For example, the progress differences located in the first three months are classified as zone $1\left(\Delta y_{i(j)} \cong 0\right)$ for project A1, with values of $0.21 \%, 1.47 \%$, and $2.96 \%$, respectively.

Table 4. Calculated values of RMSSTD, $\mathrm{R}^{2}$, and SPRSQ for project A1

\begin{tabular}{cccc}
\hline $\begin{array}{c}\text { Number of } \\
\text { clusters }\end{array}$ & RMSSTD & $\mathrm{R}^{2}$ & SPRSQ \\
\hline 2 & 1.0516 & 0.1059 & 0.9717 \\
\hline 3 & 0.3663 & 0.8658 & 0.0108 \\
\hline 4 & 0.3513 & 0.8766 & 0.0249 \\
\hline 5 & 0.3138 & 0.9015 & 0.0364 \\
\hline 6 & 0.2492 & 0.9379 & 0.0112 \\
\hline 7 & 0.2257 & 0.9491 & 0.0277 \\
\hline
\end{tabular}

Table 5. Progress differences classified in each zone of project A1

\begin{tabular}{|c|c|c|c|}
\hline $\begin{array}{l}\text { Duration } \\
\text { zone }\end{array}$ & Description & $\begin{array}{c}\text { Number of } \\
\text { month }\end{array}$ & $\begin{array}{l}\text { Progress } \\
\text { difference }\end{array}$ \\
\hline 1 & $\Delta y_{i(j)} \cong 0$ & $1,2,3$ & $\begin{array}{l}0.21 \%, 1.47 \%, \\
2.96 \%\end{array}$ \\
\hline 2 & $\Delta y_{i(j)}>0$ & $\begin{array}{l}4,5,6,7,8 \\
9,10,11,12, \\
13,14,15 \\
16\end{array}$ & $\begin{array}{l}4.51 \%, 4.98 \%, \\
5.34 \%, 5.95 \%, \\
6.55 \%, 7.20 \% \text {, } \\
7.64 \%, 8.37 \% \text {, } \\
8.42 \%, 8.26 \% \text {, } \\
8.18 \%, 6.25 \% \text {, } \\
3.57 \%\end{array}$ \\
\hline 3 & $\Delta y_{i(j)} \cong 0$ & $\begin{array}{l}17,18,19, \\
20\end{array}$ & $\begin{array}{l}0.93 \%,-1.80 \% \text {, } \\
-4.32 \%, \\
-6.80 \%\end{array}$ \\
\hline 4 & $\Delta y_{i(j)}<0$ & $\begin{array}{l}21,22,23, \\
24,25,26, \\
27,28,29, \\
30,31,32\end{array}$ & $\begin{array}{l}-8.96 \%,-11.12 \% \text {, } \\
-12.87 \%, \\
-14.58 \%, \\
-15.79 \%, \\
-16.15 \%, \\
-16.54 \%, \\
-15.76 \%, \\
-14.38 \%, \\
-12.77 \%, \\
-10.85 \%, \\
-9.02 \% \%\end{array}$ \\
\hline 5 & $\Delta y_{i(j)} \cong 0$ & $\begin{array}{l}33,34,35, \\
36\end{array}$ & $\begin{array}{l}-6.43 \%,-3.92 \%, \\
-1.82,0.00 \%\end{array}$ \\
\hline
\end{tabular}

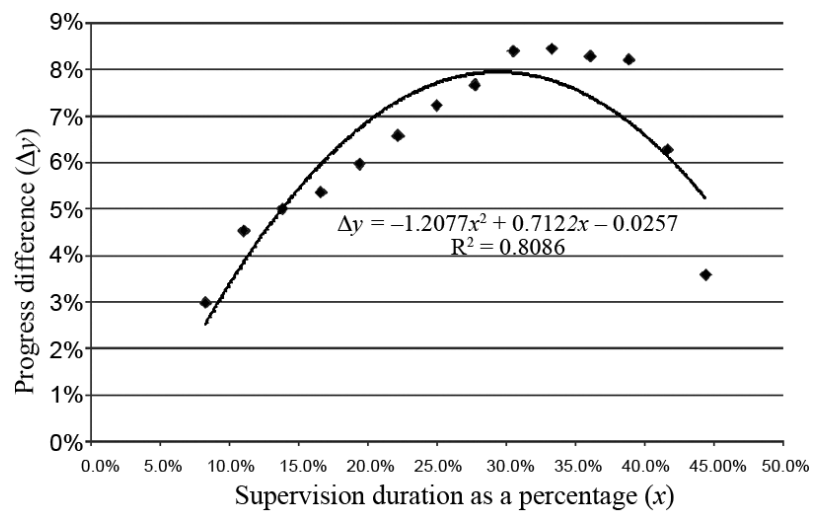

Fig. 4. Regression line for fitting the data of progress differences in zone 2 of project A1

\subsection{Step 4: Use regression analysis to derive prediction equations of the progress differences for each zone of each project}

After classifying the progress differences into five zones in each project, the progress difference data as a percentage (the $y$-axis) corresponding to the supervision duration as a percentage (the $x$-axis) are plotted in an $x-y$ plan. A regression line can be found to best represent these data. For example, Figure 4 shows the progress difference data in zone $2\left(\Delta y_{i(j)}>0\right.$, from 4 th month to 16 th month) for project A1. A quadratic regression line with a value of $\mathrm{R}$ square $=$ 0.8086 is then identified as fitting these data. The regression lines of the other four zones in project A1 can be found in a similar way, as can the zones of the other 17 projects. 
Table 6. Calculated values of $\mathrm{R}^{2}$ of the regression lines for the five zones of all 18 projects

\begin{tabular}{cccccc}
\hline \multirow{2}{*}{$\begin{array}{c}\text { Construction } \\
\text { project No. }\end{array}$} & \multicolumn{5}{c}{$\mathrm{R}^{2}$} \\
\cline { 2 - 6 } & Zone 1 & Zone 2 & Zone 3 & Zone 4 & Zone 5 \\
\hline A1 & 0.9940 & 0.8086 & 0.9999 & 0.9897 & 0.9999 \\
\hline A2 & 0.9951 & 0.9167 & 0.9921 & 0.9654 & 1.0000 \\
\hline A3 & 0.9969 & 0.9910 & 0.9998 & 0.8336 & 0.9890 \\
\hline A4 & 1.0000 & 0.8304 & 0.9964 & 0.9549 & 0.9993 \\
\hline A5 & 1.0000 & 0.1682 & 0.9886 & 0.9097 & 1.0000 \\
\hline B1 & 0.9999 & 0.9596 & 1.0000 & 0.8290 & 0.9994 \\
\hline B2 & 0.9976 & 0.9181 & 0.9984 & 0.7837 & 0.9998 \\
\hline B3 & 1.0000 & 0.9794 & 0.9988 & 0.9032 & 0.9991 \\
\hline B4 & 0.9989 & 0.9710 & 0.9710 & 0.6911 & 0.9994 \\
\hline B5 & 0.9995 & 0.9236 & 0.9969 & 0.8971 & 0.9997 \\
\hline C1 & 0.9999 & 0.9818 & 0.9994 & 0.9416 & 0.9983 \\
\hline C2 & 1.0000 & 0.6957 & 0.9987 & 0.8894 & 1.0000 \\
\hline C3 & 0.9835 & 0.7078 & 0.9934 & 0.9590 & 0.9998 \\
\hline C4 & 0.9998 & 0.8631 & 0.9342 & 0.7972 & 1.0000 \\
\hline D1 & 0.9976 & 0.8801 & 0.9841 & 0.8696 & 1.0000 \\
\hline D2 & 0.9991 & 0.3494 & 0.9612 & 0.8844 & 0.9994 \\
\hline D3 & 0.9993 & 0.7892 & 0.9994 & 0.9541 & 0.9999 \\
\hline D4 & 1.0000 & 0.8693 & 0.9986 & 0.9142 & 0.9987 \\
\hline Average R & 0.9978 & 0.8113 & 0.9895 & 0.8871 & 0.9990 \\
\hline & & & & &
\end{tabular}

Table 6 lists the calculated values of $\mathrm{R}^{2}$ of the regression lines for the five zones of all 18 projects. The average values of $R^{2}$ of the regression lines are 0.9978 , $0.8113,0.9895,0.8871$, and 0.9990 for zone 1 through zone 5 , respectively.

\subsection{Step 5: Integrate the regression results across all historical projects}

After performing Steps 1 4, the regression lines of the five zones of the 18 historical projects are developed. That is, 18 regression lines are identified for each zone. To derive a generalized regression equation for each zone $k(k=1 \sim 5)$, an average method is applied. That is, a predicted progress difference (as a percentage) for zone $k$, denoted as $\Delta y_{k}$, is derived as follows:

$$
\begin{gathered}
\Delta y_{k}=a_{k} x^{2}+b_{k} x+c_{k} ; \\
a_{k}=\left(a_{k(1)}+a_{k(2)}+\ldots+a_{k(i)}+\ldots+a_{k(18)}\right) / 18 ; \\
b_{k}=\left(b_{k(1)}+b_{k(2)}+\ldots+b_{k(i)}+\ldots+b_{k(18)}\right) / 18 ; \\
c_{k}=\left(c_{k(1)}+c_{k(2)}+\ldots+c_{k(i)}+\ldots+c_{k(18)}\right) / 18,
\end{gathered}
$$

where $x$ is the given supervision duration as a percentage, and $a_{k(i)}, b_{k(i)}$, and $c_{k(i)}$ are the constants of the derived regression equation for zone $k$ for project $i$.

Consider zone 2 as an example. Table 7 represents the derived constants of $a_{k(i)}, b_{k(i)}$, and $c_{k(i)}$ of the regression equations for zone 2 for 18 projects. Based on
Table 7. Constants of the regression equations for zone 2 of all 18 projects

\begin{tabular}{ccccc}
\hline \multirow{2}{*}{$\begin{array}{c}\text { Construction } \\
\text { project No. }\end{array}$} & \multicolumn{3}{c}{ Constants } & \multirow{2}{*}{$\mathrm{R}^{2}$} \\
\cline { 2 - 4 } A1 & -1.2077 & 0.7122 & -0.0257 & 0.8086 \\
\hline A2 & -1.1096 & 0.8120 & -0.0130 & 0.9167 \\
\hline A3 & -2.2352 & 1.1527 & -0.0547 & 0.9910 \\
\hline A4 & -2.4885 & 1.3089 & -0.0747 & 0.8304 \\
\hline A5 & -0.7329 & 0.2948 & 0.0187 & 0.1682 \\
\hline B1 & -2.5978 & 1.3967 & -0.0699 & 0.9596 \\
\hline B2 & -3.8700 & 1.9229 & -0.1019 & 0.9181 \\
\hline B3 & -2.0909 & 0.9783 & -0.0272 & 0.9794 \\
\hline B4 & -3.1150 & 1.6421 & -0.0960 & 0.9710 \\
\hline B5 & -2.5289 & 1.3666 & -0.0664 & 0.9236 \\
\hline C1 & -1.8816 & 0.9465 & -0.0172 & 0.9818 \\
\hline C2 & -1.2827 & 0.5236 & 0.0212 & 0.6957 \\
\hline C3 & -1.5664 & 0.9993 & -0.0495 & 0.7078 \\
\hline C4 & -0.7123 & 0.4805 & -0.0032 & 0.8631 \\
\hline D1 & -2.3461 & 1.3325 & -0.0353 & 0.8801 \\
\hline D2 & -0.5679 & 0.3238 & 0.0324 & 0.3494 \\
\hline D3 & -0.9605 & 0.4932 & 0.0325 & 0.7892 \\
\hline D4 & -1.5562 & 0.6345 & 0.0183 & 0.8693 \\
\hline Average & -1.8250 & 0.9623 & -0.0284 & 0.8113 \\
\hline & & & &
\end{tabular}

Table 8. Regression equations to calculate the progress differences for each zone

\begin{tabular}{cccl}
\hline $\begin{array}{c}\text { Dur- } \\
\text { ation } \\
\text { zone }\end{array}$ & $\begin{array}{c}\text { Start } \\
\text { time } \\
\text { of the } \\
\text { zone } \\
(\%)\end{array}$ & $\begin{array}{c}\text { Finish } \\
\text { time of } \\
\text { the zone } \\
(\%)\end{array}$ & Regression equations \\
\hline 1 & $0.00 \%$ & $7.46 \%$ & $\begin{array}{l}\Delta y_{k=1}=2.4316 x^{2}+0.3062 x- \\
0.0003\end{array}$ \\
\hline 2 & $7.46 \%$ & $43.41 \%$ & $\begin{array}{l}\Delta y_{k=2}=-1.8250 x^{2}+0.9623 x- \\
0.0284\end{array}$ \\
\hline 3 & $43.41 \%$ & $57.11 \%$ & $\begin{array}{l}\Delta y_{k=3}=0.4129 x^{2}-0.9969 x+ \\
0.4134\end{array}$ \\
\hline 4 & $57.11 \%$ & $89.73 \%$ & $\begin{array}{l}\Delta y_{k=4}=2.2970 x^{2}-3.4797 x+ \\
1.2056\end{array}$ \\
\hline 5 & $89.73 \%$ & $100.00 \%$ & $\begin{array}{l}\Delta y_{k=5}=-2.1319 x^{2}+4.7062 x- \\
2.5759\end{array}$ \\
\hline
\end{tabular}

Eqns (7)-(9), the constant values of $a_{k}, b_{k}$, and $c_{k}(k=2)$ are calculated as $-1.8250,0.9623$, and -0.0284 , respectively. Hence, the generalized regression equation for zone 2 is $\Delta y_{k=2}=-1.8250 x^{2}+0.9623 x-0.0284$.

In addition, the start time and finish time of a particular zone are determined by averaging the start times and finish times of the zone for all 18 historical projects. Table 8 presents the derived regression equations to calculate the progress differences for the five zones. 


\section{Estimate the engineering progress of a new project}

In the controlling stage, the derived regression equations shown in Table 8 can be applied to estimate the engineering S-curve according to the estimated construction S-curve of a new project. That is, the value of a cumulative engineering progress $\left(y_{x}\right)$ at supervision time $x$ (as a percentage) is calculated as follows:

$$
y_{x}=\operatorname{con}_{x}+\Delta y_{k},
$$

where $\operatorname{con}_{x}$ and $\Delta y_{k}$ are the cumulative construction progress and progress difference at time $x$, respectively.

\subsection{Integration of two-stage models}

Eqn (1) predicts the ES-curve in the planning stage (zone 1), while Eqn (10) represents the ES-curve in the controlling stage (zones 2 5). Table 9 summarizes the proposed final regression equations for each zone.

\subsection{Deviation measures}

Deviation between the actual and developed ES-curves is measured using the value of root-mean-square error (RMSE) (Chao, Chien 2010). The formula to calculate this measurement is as follows:

$$
R M S E=\sqrt{\frac{\sum_{j=1}^{n}\left(\text { estimated }_{j}-\text { actual }_{j}\right)^{2}}{n}},
$$

where $n$-number of progress measurements for a project; estimated $_{j}$ - estimated progress for measurement $j$; and $a c$ $t_{u a l}$ - actual progress for measurement $j$. RMSE directly measures the average deviation in percentage terms.

\section{Case study}

\subsection{Project description}

A highway mega supervision project is used to test the proposed model. This mega project (hereafter, the test project) is responsible for supervising ten construction projects. The total contractual costs of the ten construction projects is approximately 21.4 billion New Taiwan dollars (i.e. about 766.7 million US dollars; 1 US dollar is about 30 NT dollars). Each construction project ranges from 1.5 billion to 3.3 billion NT dollars. Other information related to the supervision project includes: (1) the total supervision fee is approximately 770 million NT dollars; (2) the total supervision duration is 67 months (March 2004 September 2009); and (3) the total contractual man-months of this project is about 4,800 man-months.

\subsection{Planning stage}

After awarding the test project to an engineering firm, the firm submitted a monthly engineer-allocation schedule according to their experience. Figure 5 displays the actual ES-curve of the engineering schedule for this test project during the planning stage. Currently, no methods can be used to evaluate the appropriateness of this submitted ES-curve. Now, based on the proposed model, a predicted ES-curve can be generated using Eqn (1) and is also plotted in Figure 5. Moreover, according to Eqn (11), the RMSE obtained is $0.023403(2.3403 \%)$ after comparing the actual and predicted ES-curves.

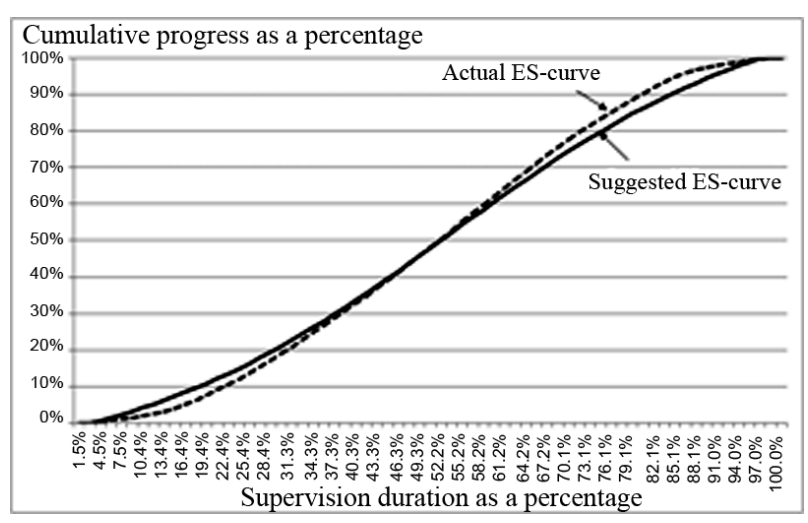

Fig. 5. Actual and suggested ES-curves of the testing project during the planning stage

Table 9. Proposed final regression equation applied in each duration zone

\begin{tabular}{ccccc}
\hline $\begin{array}{c}\text { Duration } \\
\text { zone }\end{array}$ & $\begin{array}{c}\text { Start time of the } \\
\text { zone }(\%)\end{array}$ & $\begin{array}{c}\text { Finish time of the } \\
\text { zone }(\%)\end{array}$ & Regression equations & Applied stage \\
\hline 1 & $0.00 \%$ & $7.46 \%$ & $y_{x}=-0.126+\frac{1.2911}{1+e^{-\left(\frac{x-0.5352}{0.2277}\right)}}$ & Planning stage \\
\hline 2 & $7.46 \%$ & $43.41 \%$ & $\begin{array}{l}\Delta y_{k=2}=-1.8250 x^{2}+0.9623 x-0.0284 \\
y_{x}=c o n_{x}+\Delta y_{k}\end{array}$ & Controlling stage \\
\hline 3 & $43.41 \%$ & $57.11 \%$ & $\begin{array}{l}\Delta y_{k=3}=0.4129 x^{2}-0.9969 x+0.4134 \\
y_{x}=\operatorname{con}_{x}+\Delta y_{k}\end{array}$ & Controlling stage \\
\hline 4 & $57.11 \%$ & $\begin{array}{l}\Delta y_{k=4}=2.2970 x^{2}-3.4797 x+1.2056 \\
y_{x}=\operatorname{con}_{x}+\Delta y_{k}\end{array}$ & Controlling stage \\
\hline 5 & $89.73 \%$ & $100.00 \%$ & $\begin{array}{l}\Delta y_{k=4}=-2.1319 x^{2}+4.7062 x-2.5759 \\
y_{x}=\operatorname{con}_{x}+\Delta y_{k}\end{array}$ & Controlling stage \\
\hline
\end{tabular}




\subsection{Controlling stage}

As the test project progresses, the ten construction projects were subsequently tendered and the construction work followed. In Figure 6, the dotted S-curve presents the actual integrated construction schedule by weighting the ten individual construction schedules based on their corresponding percentages of construction costs for the total construction costs. For example, an integrated construction progress of this actual construction schedule is the sum of the weighted construction progresses $\left(=p_{i} \times \operatorname{con}_{i(j)}\right)$ of the ten construction projects. Additionally, Figure 6 also plots the actual ES-curve of this test project.

At this stage, the construction schedule is known, so the second-stage model is applied. Hence, Figure 6 presents the suggested ES-curve based on the derived regression equations (Table 9). According to Eqn (11), the RMSE obtained is $0.035682(3.5682 \%)$ after comparing the actual and suggested ES-curves.

Comparing the actual and suggested ES-curves shown in Figure 6, the major difference is that the latter allocates supervision engineers with respect to the construction progress. For instance, in approximately $43.3 \%$ of the duration of the supervision, slow progress of construction work occurred. At that time, the suggested ES-curve correspondingly slowed down the allocation of additional supervision engineers, while the actual ES-curve did not.

\subsection{Discussions}

After conducting the case study, several lessons are identified from discussions with a manager of the case-study firm and a section officer of the TANEEB. These lessons are summarized as follows:

1. Under a cost-plus-fixed-fee contract, engineering firms tend to consume as many of the total man-months as possible in the early stages. As a result, the engineering man-months are likely to be insufficient in the latter stages of the project when a large amount of construction work still has not been done. In such a case, the TANEEB will

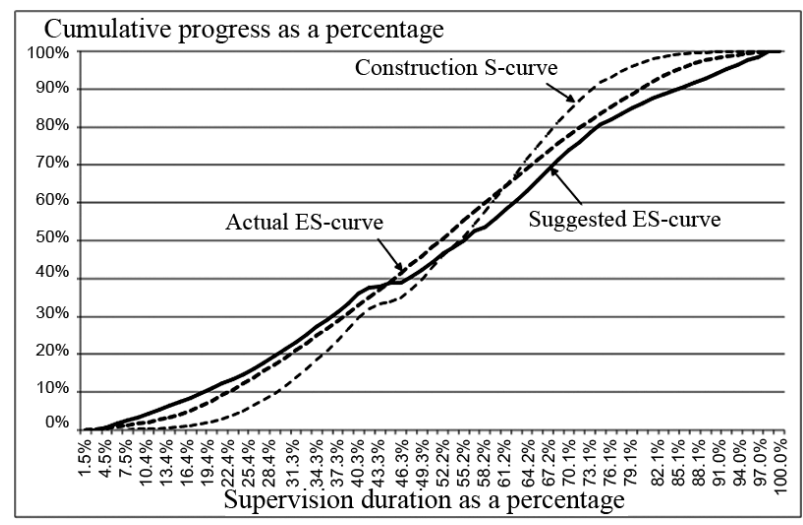

Fig. 6. Actual and suggested ES-curves of the test project during the control stage usually not grant additional cost compensations to the engineering firm, because allocating engineers appropriately is considered to be firm's responsibility. For example, in the case study, the total construction duration was actually extended and no cost compensations were granted to the engineering firm. Supposing the firm could reduce the manmonths in the controlling stage, when the construction delay occurred (as suggested by the proposed model), engineering costs should not be overrun. The ES-curves generated by the proposed model should help the engineering firm improve its resource allocation decisions.

2. Currently, the TANEEB reviews the submitted engineering schedules based on experience. The proposed model can also provide an efficient reference to support the reviewing process. That is, the stage- 1 ES-curve can help to review the submitted engineering schedule, while the stage- 2 curve can check if the initial (as-planned) engineering schedule should be updated to reflect the construction status.

As indicated in Section 3.1, six historical supervision projects were selected by the research team for developing the ES-curve model in the planning stage. These projects were selected mainly for two reasons. First, data for engineer allocation schedules (similar to the data shown in Table 1) of these projects were thoroughly documented for analysis. Second, the approved schedules of these projects were successfully implemented as target schedules to assign supervision engineers during the planning stage. However, according to some practitioners involved in these projects, these approved schedules were occasionally unsatisfactory during the controlling stage. For instance, additional engineers over a specified target amount were not allowed when construction work was accelerating. Therefore, the proposed model is divided into two stages for developing ES-curves.

\section{Conclusions}

This study has illustrated the problem of assigning supervision engineers under a cost-plus-fixed-fee contract in a highway construction project. Assigning an appropriate number of supervision engineers is critical to the profitability of an engineering firm and the quality assurance of construction projects. The proposed two-stage model has contributed to developing engineering S-curves to resolve this engineer allocation problem for supervision projects.

There are possible areas for future research. First, the proposed model may be modified so that it applies to building projects. Notably however, the supervision work of a building project is normally contracted based on a percentage fee method. Second, the current planningstage model is developed based on six mega projects, while the current controlling-stage model is designed according to four mega projects and 18 construction 
projects. Data from additional projects should be collected and included into the regression database. Third, as mentioned earlier, several factors influence the engineer allocations. We recommend that future research further clarify the effects of these factors and incorporate them into the development of the planning-stage model. Fourth, other optimization theories, such as genetic algorithms, may be substituted for regression analysis in a search for improved solutions.

\section{Acknowledgements}

The authors would like to thank the editor and the reviewers for their careful evaluation and thoughtful suggestions. The authors also thank the National Science Council of Taiwan (Contract No. NSC101-2221-E-009-137-MY3) for financially supporting this research. In addition, Mr. Shin-Hung Yeh and Mr. Jong-Yeuan Chou are appreciated for providing valuable data and sharing their experience in this study.

\section{References}

Bubshait, A. A.; Al-Said, F. A.; Abolnour, M. M. 1998. Design fee versus design deficiency, Journal of Architectural Engineering 4(2): 44-46.

http://dx.doi.org/10.1061/(ASCE)1076-0431(1998)4:2(44)

Carr, P. G.; Beyor, P. S. 2005. Design fees, the state of the profession, and a time for corrective action, Journal of Management in Engineering 21(3): 110-117.

http://dx.doi.org/10.1061/(ASCE)0742-597X(2005)21:3(110)

Chao, L. C.; Chien, C. F. 2009. Estimating project S-curves using polynomial function and neural networks, Journal of Construction Engineering and Management 135(3): $169-177$.

http://dx.doi.org/10.1061/(ASCE)0733-9364(2009)135:3(169)

Chao, L. C.; Chien, C. F. 2010. A model for updating project S-curve by using neural networks and matching progress, Automation in Construction 19(1): 84-91. http://dx.doi.org/10.1016/j.autcon.2009.09.006

Chen, C. H. 2011. Model for allocating monthly supervision manpower of engineering firms: MS Thesis. Department of Civil Engineering, National Chiao Tung University, Taiwan.

Cheng, Y. M.; Yu, C. H.; Wang, H. T. 2011. Short-interval dynamic forecasting for actual S-curve in the construction phase, Journal of Construction Engineering and Management 137(11): 933-941.

http://dx.doi.org/10.1061/(ASCE)CO.1943-7862.0000358

Cioffi, D. F. 2005. A tool for managing projects: an analytic parameterization of the S-curve, International Journal of Project Management 23(3): 215-222. http://dx.doi.org/10.1016/j.ijproman.2004.08.001

Cioffi, D. F. 2006. Designing project management: a scientific notation and an improved formalism for earned value calculations, International Journal of Project Management 24(2): 136-144. http://dx.doi.org/10.1016/j.ijproman.2005.07.003

Draper, N. R.; Smith, H. 1998. Applied regression analysis. $3^{\text {rd }}$ ed. John Wiley and Sons, New York. 736 p.

Fisher, D.; Xu, L.; Zard, N. 1992. Ordering effects in clustering, in Proceedings of the Ninth International Conference on Machine Learning, 1992, Morgan Kaufmann, San Mateo, CA, 163-168.
Feldmann, M. L.; Chrusciel, D.; Pohlmann, A.; Shelley, II, M. C.; McCool, K.; Morton, A. D.; Ahoy, C. K. 2008. Architectural and engineering fees from the public institutional perspective, Journal of Management in Engineering 24(1): 1-11.

http://dx.doi.org/10.1061/(ASCE)0742-597X(2008)24:1(2)

Fleming, Q. W.; Koppelman, J. M. 2005. Earned value project management. $3^{\text {rd }}$ ed. Project Management Institute, Newtown Square, PA. 232 p.

Flyvbjerg, B.; Holm, M.; Buhl, S. 2002. Underestimating costs in public works projects: error or lie? Journal of the American Planning Association 68(3): 279-295. http://dx.doi.org/10.1080/01944360208976273

Gransberg, D. D.; Puerto, C. L.; Humphrey, D. 2007. Relating cost growth from the initial estimate to design fee for transportation projects, Journal of Construction Engineering and Management 133(6): 404-408.

http://dx.doi.org/10.1061/(ASCE)0733-9364(2007)133:6(404)

Hoxley, M. 2000. Are competitive fee tendering and construction professional service quality mutually exclusive? Construction Management and Economics 18(5): 599-605.

http://dx.doi.org/10.1080/014461900407400

Li, C. Y. 2004. Model analysis of manpower optimization assignments for construction inspection project: MS Thesis. Department of Civil Engineering, National Central University, Taiwan.

Ling, Y. Y. 2004. Consultancy fees: dichotomy between A/Es need to maximize profit and employers' need to minimize cost, Journal of Professional Issues in Engineering Education and Practice 130(2): 120-123.

http://dx.doi.org/10.1061/(ASCE)1052-3928(2004)130:2(120)

Maravas, A.; Pantouvakis, J. P. 2012. Project cash flow analysis in the presence of uncertainty in activity duration and cost, International Journal of Project Management 30(3): 374-384.

http://dx.doi.org/10.1016/j.ijproman.2011.08.005

Milligan, G. W. 1980. An examination of the effect of six types of error perturbation on fifteen clustering algorithms, Psychometrika 45(3): 325-342. http://dx.doi.org/10.1007/BF02293907

Miskawi, Z. 1989. An S-curve equation for project control, Construction Management and Economics 7(2): 115-124. http://dx.doi.org/10.1080/01446198900000016

Molenaar, K. R. 2005. Programmatic cost risk analysis for highway megaprojects, Journal of Construction Engineering and Management 131(3): 343-353.

http://dx.doi.org/10.1061/(ASCE)0733-9364(2005)131:3(343)

Ogunlana, S.; Lim, J.; Saeed, K. 1998. Desman: a dynamic model for managing civil engineering design projects, Computers and Structures 67(5): 401-419. http://dx.doi.org/10.1016/S0045-7949(97)00148-X

Ratkowsky, D. A. 1990. Handbook of nonlinear regression models. New York: Marcel Dekker, Inc. 241 p.

Sharma, S. 1996. Applied multivariate techniques. New York: John Wiley and Sons. 512 p.

TANEEB. 2012. Annual budget report. Taiwan Area National Expressway Engineering Bureau, Ministry of Transportation and Communications, Taiwan.

Warburton, R. D. H. 2011. A time-dependent earned value model for software projects, International Journal of Project Management 29(8): 1082-1090. http://dx.doi.org/10.1016/j.ijproman.2011.02.008

Yang, I. T.; Chou, J. S. 2011. Multi-objective optimization for manpower assignment in consulting engineering firms, Applied Soft Computing 11(1): 1183-1190. http://dx.doi.org/10.1016/j.asoc.2010.02.016 
Shih-Hsu WANG. Assistant Professor in the Department of Civil Engineering at ROC Military Academy, Taiwan. He received his $\mathrm{PhD}$ degree from the Department of Civil Engineering at National Chiao Tung University. His research interests include national competitiveness and construction consultant service.

Wei-Chih WANG. Professor in the Department of Civil Engineering at National Chiao Tung University, Taiwan. He is a member of the Construction Management Association of Taiwan. His research interests include construction procurement, engineering management, building information modelling, high-tech facility management, and construction simulation.

Pei-Yuan HSU. He received his MS degree from the Department of Civil Engineering at National Chiao Tung University, Taiwan. His research interests include building information modelling and structural engineering.

Ci-Hao CHEN. He received his MS degree from the Department of Civil Engineering at National Chiao Tung University, Taiwan. His research interests include engineering management and resource allocation management.

Kun-Chi WANG. PhD student in the Department of Civil Engineering at National Chiao Tung University, Taiwan. His research interests include building information modelling and construction management. 